\title{
LETTER
}

\section{Is early treatment of disseminated intravascular coagulation beneficial in septic patients?}

\author{
Hideo Wada ${ }^{1 *}$, Takeshi Matsumoto ${ }^{2}$, Yoshiki Yamashita ${ }^{3}$ and Tsuyoshi Hatada ${ }^{4}$ \\ See related research by Gando et al., http://ccforum.com/content/17/3/R111
}

We read with interest the recent issue of Critical Care, particularly the article by Gando and colleagues [1] about the validation of the scoring systems for disseminated intravascular coagulation (DIC). Mortality in patients with DIC according to diagnostic criteria of the Japanese Association of Acute Medicine (JAAM; 31.8\%) was similar to that in patients with International Society of Thrombosis and Haemostasis (ISTH) overt-DIC (30.1\%). A previous report [2] showed different results; mortality was significantly higher in patients with overt-DIC (34.4\%) than in those with JAAM DIC (17.2\%). The difference in the mortality between this report [1] and the previous report [2] may depend on not only the sensitivity of the diagnostic criteria, but also on the antithrombotic therapy (ATT).
Although most patients were considered to be treated with ATT at the early stage of DIC in this study [1], those treated in the other study [2] had late stage DIC [3]. As the presence of neutrophil extracellular traps [4] and hypercoagulation in DIC induce localization of infection, the administration of ATT may spread the infection. Therefore, ATT may worsen sepsis in the early stage of the disease while improving hemostatic abnormalities following organ failure in patients with severe sepsis. Overall, ATT may not improve the outcomes of patients with sepsis in the early stage, although it can potentially improve the outcomes of those with overt-DIC (Figure 1). The timing of ATT may be too early in septic patients when using the JAAM diagnostic criteria and too late in those with ISTH overt-DIC.

\section{Authors' response Satoshi Gando}

We appreciate the interest of Wada and colleagues in our recently published article studying the JAAM DIC scoring system in patients with severe sepsis [1]. It is now widely accepted that localized platelet and fibrin thrombosis at the site of infection is a physiologic reaction that protects against dissemination of microorganisms and pathogen-associated molecular patterns derived from them into the systemic circulation, which is now called immunothrombosis [5]. Therefore, we agree that early anticoagulation therapy for sepsis probably induces uncontrolled immunothrombosis, leading to pathological systemic DIC. Fourrier [6] clearly demonstrated that the target for the treatment of sepsis is not sepsis itself, but DIC as a result of the overwhelming effects of sepsis on immunothrombosis. The mortality rate of the severe sepsis patients who met the JAAM DIC criteria was $31.8 \%$, and the Kaplan-Meier curves clearly demonstrated that there was a lower 1-year survival rate in the JAAM DIC patients, which supports our opinion that the DIC patients diagnosed by the JAAM scoring system should be treated as early as possible [1]. The differences in the mortality rate between the two studies pointed out by Wada and colleagues were due to differences in the subjects included in the two studies [1,2]. Our previous study included diverse clinical conditions that were associated with DIC [2], but the inclusion criteria for the current study were restricted to only severe sepsis patients [1].

\footnotetext{
* Correspondence: wadahide@clin.medic.mie-u.ac.jp
${ }^{1}$ Department of Molecular and Laboratory Medicine, Mie University Graduate

* Correspondence: wadahide@clin.medic.mie-u.ac.jp
${ }^{1}$ Department of Molecular and Laboratory Medicine, Mie University Graduate School of Medicine, Tsu, Mie 514-8507, Japan

Full list of author information is available at the end of the article
}

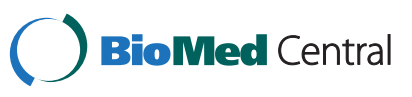

(c) 2014 Wada et al.; licensee BioMed Central Ltd. This is an Open Access article distributed under the terms of the Creative Commons Attribution License (http://creativecommons.org/licenses/by/4.0), which permits unrestricted use, distribution, and reproduction in any medium, provided the original work is properly credited. The Creative Commons Public Domain Dedication waiver (http://creativecommons.org/publicdomain/zero/1.0/) applies to the data made available in this article, unless otherwise stated. 


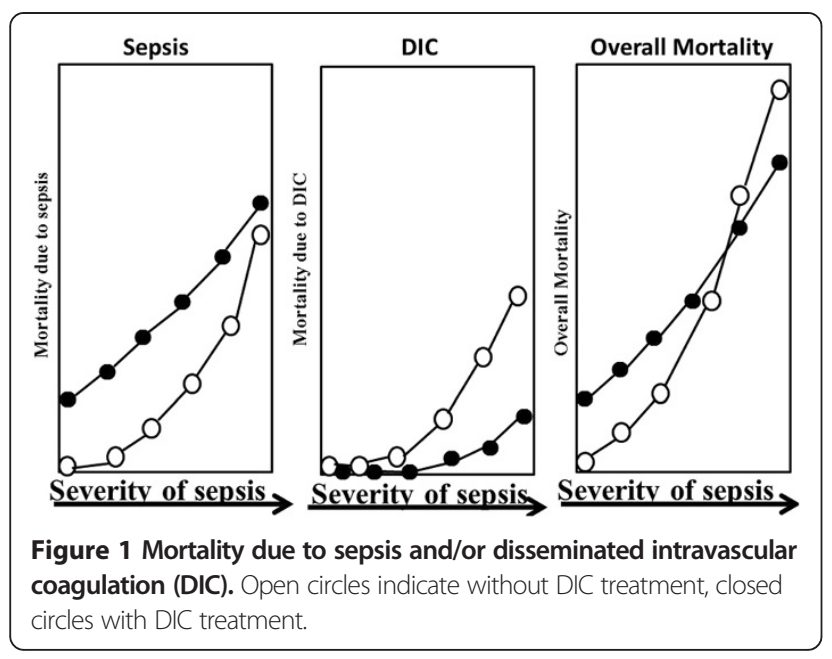

\section{Abbreviations}

ATT: antithrombotic therapy; DIC: disseminated intravascular coagulation; ISTH: International Society of Thrombosis and Haemostasis; JAAM: Japanese Association for Acute Medicine.

\section{Competing interests}

The authors declare that they have no competing interests.

\section{Acknowledgments}

This work was supported in part by a Grant-in-Aid from the Ministry of Health, Labour and Welfare of Japan for Blood Coagulation Abnormalities and the Ministry of Education, Culture, Sports, Science and Technology of Japan.

\section{Author details}

'Department of Molecular and Laboratory Medicine, Mie University Graduate School of Medicine, Tsu, Mie 514-8507, Japan. ${ }^{2}$ Blood Transfusion Center, Mie University Hospital, Tsu, Mie 514-8507, Japan. ${ }^{3}$ Department of Hematology and Oncology, Mie University School of Medicine, Tsu, Mie 514-8507, Japan. ${ }^{4}$ Emergency Critical Care Center, Mie University Hospital, Tsu, Mie 514-8507, Japan.

Published: 04 Jul 2014

\section{References}

1. Gando S, Saitoh D, Ogura H, Fujishima S, Mayumi T, Araki T, Ikeda H, Kotani J, Kushimoto S, Miki Y, Shiraishi S, Suzuki K, Suzuki Y, Takeyama N, Takuma K, Tsuruta R, Yamaguchi Y, Yamashita N, Aikawa N, for Japanese Association for Acute Medicine Sepsis Registry Study Group: A multicenter, prospective validation study of the Japanese Association for Acute Medicine disseminated intravascular coagulation scoring system in patients with severe sepsis. Crit Care 2013, 17:R111.

2. Gando S, Saitoh D, Ogura H, Mayumi T, Koseki K, Ikeda T, Ishikura H, Iba T, Ueyama M, Eguchi Y, Ohtomo Y, Okamoto K, Kushimoto S, Endo S, Shimazaki S, Japanese Association for Acute Medicine Disseminated Intravascular Coagulation (JAAM DIC) Study Group: Natural history of disseminated intravascular coagulation diagnosed based on the newly established diagnostic criteria for critically ill patients: results of a multicenter, prospective survey. Crit Care Med 2008, 36:145-150.

3. Wada H, Thachil J, Di Nisio M, Mathew P, Kurosawa S, Gando S, Kim HK Nielsen JD, Dempfle CE, Levi M, Toh CH, The Scientific Standardization Committee on DIC of the International Society on Thrombosis Haemostasis: Guidance for diagnosis and treatment of DIC from harmonization of the recommendations from three guidelines. J Thromb Haemost 2013, 11:761-767.
4. Brinkmann V, Reichard U, Goosmann C, Fauler B, Uhlemann Y, Weiss DS, Weinrauch Y, Zychlinsky A: Neutrophil extracellular traps kill bacteria. Science 2004, 303:1532-1535

5. Engelman B, Massberg S: Thrombosis as an intravascular effector of innate immunity. Nat Rev Immunol 2013, 13:34-45.

6. Fourrier F: Severe sepsis, coagulation, and fibrinolysis: dead end or one way? Crit Care Med 2012, 40:2704-2708.

\section{$10.1186 /$ cc13971}

Cite this article as: Wada et al.: Is early treatment of disseminated intravascular coagulation beneficial in septic patients? Critical Care 2014, 18:447 